\title{
Effects of Egg White Consumption on Allergy, Immune Modulation, and Blood Cholesterol Levels in BALB/C Mice
}

\author{
Hyuk Song ${ }^{\dagger}$, Jin-Ki Park ${ }^{1 \dagger}$, Hyoun Wook Kim ${ }^{1}$, and Won-Young Lee* \\ Division of Food Bioscience, RIBH, College of Biomedical \& Health Science, \\ Konkuk University, Chung-ju 380-701, Korea \\ ${ }^{1}$ National Institute of Animal Science, RDA, Suwon 441-706, Korea
}

\begin{abstract}
We previously demonstrated that water-soluble egg yolk extract is not related to elevation of serum immunoglobulin E, which can initiate allergic reactions; however, it increases the level of high density lipoprotein (HDL)-cholesterol and the activity of B lymphocytes. In this study, egg white (EW) was fed to BALB/c mice to determine its influence on growth efficiency, immune modulation, and changes in serum lipid levels. A total of 50 five-wk-old BALB/c male mice were divided into 5 groups, 4 of which were fed 0, 10, 50, or $100 \mathrm{mg} / \mathrm{d}$ EW for $4 \mathrm{wk}$. Mice with an uptake of 10, $50 \mathrm{and} 100 \mathrm{mg} / \mathrm{d}$ EW showed no significant changes in daily weight gain, feed efficiency rate, or populations of white blood cells. However, the activities of both B and T lymphocytes were significantly increased in all three EW groups at the final week of treatment. Interestingly, serum levels immunoglobulin E were not altered by EW consumption, but the IgG level was significantly increased in the $100 \mathrm{mg} / \mathrm{d}$ EW group. Serum lipid profile analyses showed no significant changes in total cholesterol, HDL, low density lipoprotein, or triglyceride levels by EW consumption. Taken together, these data demonstrate that consumption of EW promotes immune cell activities and the upregulation of serum IgG levels. However, we found no changes in serum lipid profiles and IgE levels. Therefore, our study suggests that consumption of EW might not be related to the risk of food allergy, but could be an excellent candidate for the maintenance of physiological homeostasis.
\end{abstract}

Keywords: egg white, cholesterol, immunoglobulin, lymphocyte activation, allergen

\section{Introduction}

Chicken egg is one of the most commonly available, economical foods. Eggs provide essential nutrients including high quality proteins, unsaturated fats, folate, and various vitamins, which are regarded as protective factors (Song et al., 2000). However, eggs contain high levels of cholesterol and many food allergens and, therefore, their high daily consumption must be limited.

Eggs serve as a major source of dietary cholesterol, containing approximately $210 \mathrm{mg}$ cholesterol per egg (Song et al., 2000). Human metabolic studies have shown that dietary cholesterol from eggs can raise serum levels of low density lipoprotein cholesterol (LDL-C), a wellestablished independent risk factor for cardiometabolic

\footnotetext{
${ }^{\dagger}$ These authors contributed equally to this work.

*Corresponding author: Won-Young Lee, Department of Food Bioscience, College of Biomedical \& Health Science, Konkuk University, Chung-ju 380-701, Korea. Tel: +82-43-840-3522, E-mail: abseng@kku.ac.kr
}

and cardiovascular diseases (Hu et al., 1999; Weggemans et al., 2001). In contrast, egg consumption in free-living populations does not increase blood cholesterol levels (Kritchevsky and Kritchevsky, 2000). A recent study also suggested that the consumption of water-soluble egg yolk extract (WSEYE) decreases daily weight gain and triglyceride (TG) levels, but increases the level of high density lipoprotein cholesterol (HDL-C) (Lee et al., 2013). Moreover, the American Heart Association has retracted the recommendation to limit egg consumption in their guidelines (Kritchevsky, 2004).

Allergy from egg consumption has been shown to be the most common food allergy in children with atopic dermatitis (Sampson, 2004). A recent meta-analysis of the prevalence of food allergy estimated that egg allergy affects $0.5-2.5 \%$ of young children (Rona et al., 2007). However, oral immunotherapy can desensitize a large proportion of children with egg allergy (Burks et al., 2012). Compared to allergic reactions against egg white (EW), reactions against egg yolk (EY) proteins are more frequent (Anet et al., 1985). Ovomucoid, ovalbumin, ovotransfer- 
rin, and lysozyme have been identified as major allergens in EW (Bernhisel-Broadbent et al., 1994; Heine et al., 2006). In addition, egg-yolk contains certain allergens including alpha livetin, vitelline, and apoprotein B; however, their roles as allergens remain to be elucidated (Szepfalusi et al., 1994).

Although eggs have beneficial and detrimental biological effects, the effects of EW, which excludes the lipid cholesterol of egg yolk, on diet, blood cholesterol levels, and immune modulation are yet to be clarified in normal healthy animal models. In the present study, various concentrations of EW were fed to mice to determine the correlation between EW consumption and health parameters by measuring changes in body weight (BW), blood cholesterol levels, sensitivity to allergy, and immunomodulatory activity. Furthermore, we discuss the advantages and disadvantages of EW consumption.

\section{Materials and Methods}

\section{Preparation of EW}

Commercially available normal fresh eggs were obtained from a local egg farm. The egg white was collected while excluding the yolk. The EW was freeze-dried using a freeze dryer (Ilshintech, Korea) and resuspended in distilled water (DW).

\section{Animals}

All animal care protocols were approved by the Konkuk University Institutional Animal Care and Use Committee (Approval No.: KU13144-1). A total of 50 male BALB/c mice (5 wk old; Nara Biotech Co., Korea) were housed in a conventional temperature- and humidity-controlled room, and provided standard laboratory food and water.

\section{Experimental design}

Five groups of mice (10 mice per group) were used in the study. Group 1 animals were treated for 4 wk with an oral dose of $1 \times \mathrm{DW}$ as the vehicle. Group 2, 3, and 4 animals were treated for $3 \mathrm{~d}$ a week for 4 wk with an oral dose of 10,50 , and $100 \mathrm{mg} / \mathrm{d} \mathrm{EW}$, respectively. Group 5 animals were a model for elevated production of serum IgE. Briefly, the fur on the backs of the mice was removed at $1 \mathrm{~d}$ prior to treatment with 1-chloro-2,4-dinitrobenzene (DNCB) (Sigma, USA). The first treatment consisted of $200 \mu \mathrm{L}$ of a $1 \%$ DNCB solution (dissolved in acetone:olive oil at 3:1), whereas a second treatment with $0.1 \% \mathrm{DNCB}$ was applied $4 \mathrm{~d}$ after the first treatment.
Additional treatments with $0.1 \%$ DNCB were then conducted once every $3 \mathrm{~d}$ for $4 \mathrm{wk}$. Changes in BW and the average feed intake of the mice were measured every $7 \mathrm{~d}$ during EW treatment.

\section{Lymphocyte and serum preparation}

Ten mice from each experimental group were sequentially anesthetized using 2.5\% $(v / v)$ avertin, and blood samples were collected by direct heart puncture. Approximately $0.2 \mathrm{~mL}$ blood was collected into tubes containing ethylenediaminetetraacetic acid (EDTA) (Becton Dickinson, USA), and $0.1 \mathrm{~mL}$ whole blood was mixed with 0.1 $\mathrm{mL}$ Histopaque-1077 (Sigma) and centrifuged at 1,200 $\mathrm{g}$ for $20 \mathrm{~min}$. The lymphocytes were carefully collected from the middle phase of the gradient. To separate the serum, $0.5 \mathrm{~mL}$ whole blood was incubated for $1 \mathrm{~h}$ at room temperature and then centrifuged at $1,200 \mathrm{~g}$ for $15 \mathrm{~min}$. The supernatant was carefully collected and stored at $-70^{\circ} \mathrm{C}$.

\section{Blood cell analysis}

The collected whole blood samples were inverted several times to prevent coagulation in an EDTA-coated tube. The concentration of mouse white blood cells and the percentages of neutrophils, lymphocytes, eosinophils, basophils, and monocytes were compared among the four treatment groups. Samples were analyzed immediately by an ADVIA 2120 hematology system (Siemens, Germany), according to the manufacturer's instructions.

\section{Measurement of lymphocyte activation during EW treatment}

Isolated lymphocytes $\left(1 \times 10^{5}\right.$ cells) from each treatment group were seeded in a 96-well plate and incubated for 1 $\mathrm{h}$ at $37^{\circ} \mathrm{C}$. Lipopolysaccharide $(2.5 \mu \mathrm{g} / \mathrm{mL})$ was added to the cultured cells to identify B lymphocyte activity, and $2.5 \mu \mathrm{g} / \mathrm{mL}$ concanavalin A was added to assess $\mathrm{T}$ lymphocyte activity. The cells were then incubated for $48 \mathrm{~h}$. Cell viability and proliferation were analyzed using an EZ-cytotox kit (Daeil Lab Service, Korea) according to the manufacturer's instructions. The cell proliferation rate was determined using a microplate reader at an absorbance of $550 \mathrm{~nm}$.

\section{Analysis of immunoglobulin}

The immunoglobulin $\mathrm{G}(\mathrm{IgG})$ and immunoglobulin $\mathrm{E}$ (IgE) concentrations in the whole blood samples were measured by a mouse IgG and IgE enzyme-linked immunosorbent assay using a quantitation kit (Bethyl Laboratory Inc., USA) in accordance with the manufacturer's ins- 
tructions. Serum IgG and IgE concentrations were evaluated by comparison with concentrations of serial dilutions of each IgG and IgE standard protein provided in the kit.

\section{Cholesterol and lipid analyses, and liver functional testing}

Total cholesterol (TC), HDL-C, and TG concentrations were determined enzymatically using kits and in accordance with the manufacturer's instructions (Asan Pharmaceutical Co., Korea). The LDL-C concentration was measured by Friedwald's method (Friedwald et al., 1972). Glutamic oxaloacetic transaminase (GOT) and glutamic pyruvic transaminase (GPT) concentrations were measured by Reitman-Frankel's method (Reitman and Frankel, 1957).

\section{Statistical analysis}

Data were analyzed by one-way analysis of variance using SPSS statistical package ver. 21.0 for Windows. Turkey's multiple comparison test was used for comparisons between groups. All data are expressed as the mean \pm standard deviation. The null hypothesis was rejected when the probability was $p<0.05$.

\section{Results and Discussion}

\section{Body weight gain, feed intake, and feed efficiency rate}

The BW gain, feed intake, and feed efficiency rate (FER) were compared daily in mice that consumed $0,10,50$, or $100 \mathrm{mg} / \mathrm{d}$ EW. As shown in Table 1, daily BW gains of 0 , 10,50 , and $100 \mathrm{mg} / \mathrm{d} \mathrm{EW}$, and DNCB treatments were $0.14 \pm 0.01 \mathrm{~g}, 0.12 \pm 0.03 \mathrm{~g}, 0.12 \pm 0.04 \mathrm{~g}, 0.15 \pm 0.04 \mathrm{~g}$, and $0.11 \pm 0.06 \mathrm{~g}$. The daily BW gain of the 10,50 , and 100 $\mathrm{mg} / \mathrm{d}$ EW- and DNCB-treated groups showed no significant change $(p<0.05)$ compared with that in the control. Feed intakes by mice with $0,10,50$, or $100 \mathrm{mg} / \mathrm{d} \mathrm{EW}$ and DNCB treatments were $3.59 \pm 0.13 \mathrm{~g}, 3.51 \pm 0.12 \mathrm{~g}, 3.53 \pm$ $0.25 \mathrm{~g}, 3.65 \pm 0.21 \mathrm{~g}$, and $4.51 \pm 0.30 \mathrm{~g}$. In the group treated with DNCB, there was a significant increase in the average feed intake for 4 wk (Table 1). Analysis of the FER showed a significantly decrease in the DNCB-treated group, whereas EW-treated groups showed no significant change of the FER $(p<0.05)$ compared with that in the control (Table 1). These data are not consistent with the results of previous reports showing that egg and egg extract intake significantly reduces BW (Lee et al., 2013; Vander Wal et al., 2005). Recent study showed that dietary EW decreased feed intake, BW gain and fat accumulation in liver, muscle and adipose tissues, but muscle weight was increased (Ochiai and Matsuo, 2014). Compare to previous observation, only BW gain and feed intake were analyzed, whereas fat/muscle composition was not determined in the present study. Therefore it is postulated that EW consumption would not be related to weight gain and feed intake, but be possibly affect in fat/muscle composition changes. Taken together, our results suggest that a high daily consumption of EW does not increase BW.

\section{Changes in blood immune cell populations and lymphocyte activation}

To determine whether EW influences populations of blood immune cells, we analyzed changes in the number of lymphocytes, neutrophils, eosinophils, basophils, and monocytes. There were no significant differences in the populations of lymphocytes, neutrophils, eosinophils, basophils, and monocytes among the EW treatment groups (Fig. 1). The percentage of lymphocytes was significantly decreased and neutrophils were significantly increased in the DNCB-treated group after 4 wk of treatment (Fig. 1). Neutrophils mainly play a role in acute inflammation because of their relatively short half-life. The neutrophil to lymphocyte ratio (NLR) is the measure of balance between neutrophil and lymphocyte levels in the body and an indicator of systemic inflammation (Zahorec, 2001). A recent study described that NLR provides a reliable inflammatory index in coronary artery disease (CAD) and type 2 diabetes patients (Safak et al., 2013). In this study, DNCB was used for induction of an allergic reaction, but DNCB treatment also initiated CAD.

The activation of $\mathrm{B}$ and $\mathrm{T}$ lymphocytes was compared among control and EW-treated groups. The effect of EW $(10,50$, and $100 \mathrm{mg} / \mathrm{d})$ on $\mathrm{B}$ and $\mathrm{T}$ lymphocyte activation

Table 1. Changes in daily body weight gain and daily feed intake in mice treated with egg white (EW)

\begin{tabular}{cccccc}
\hline \hline Treat $(\mathrm{mg} / \mathrm{d})$ & 0 & 10 & 50 & 100 & DNCB \\
\hline Weight gain (g/d) & $0.14 \pm 0.01$ & $0.12 \pm 0.03$ & $0.12 \pm 0.03$ & $0.15 \pm 0.04$ & $0.11 \pm 0.06$ \\
Feed intake (g/d) & $3.59 \pm 0.13$ & $3.51 \pm 0.12$ & $3.53 \pm 0.25$ & $3.65 \pm 0.21$ & $4.51 \pm 0.30^{*}$ \\
FER & $0.04 \pm 0.01$ & $0.04 \pm 0.01$ & $0.03 \pm 0.01$ & $0.04 \pm 0.01$ & $0.02 \pm 0.01^{*}$
\end{tabular}

$p$-values were calculated between $0 \mathrm{mg} / \mathrm{d}$ (control) and each EW treatment for $4 \mathrm{wk}\left({ }^{*} p<0.05, \mathrm{n}=10\right)$. FER: feed efficiency rate (body weight gain/feed intake); EW: egg white; DNCB: 1-chloro-2,4-dinitrobenzene. 
A

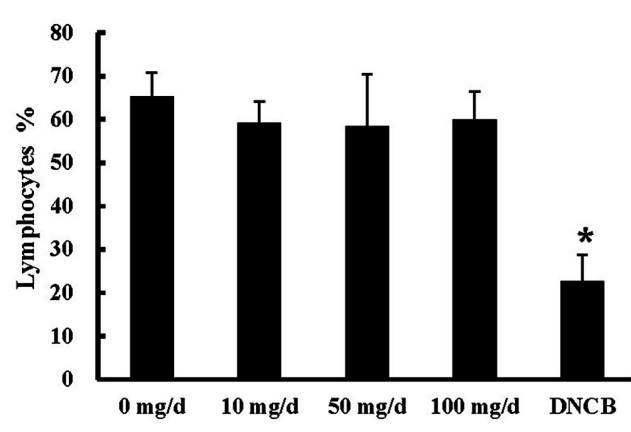

C

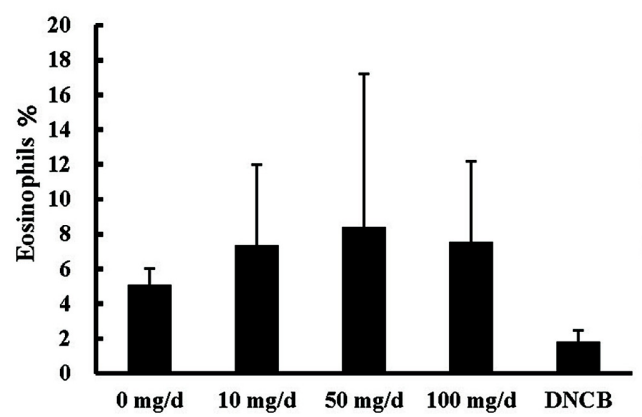

B

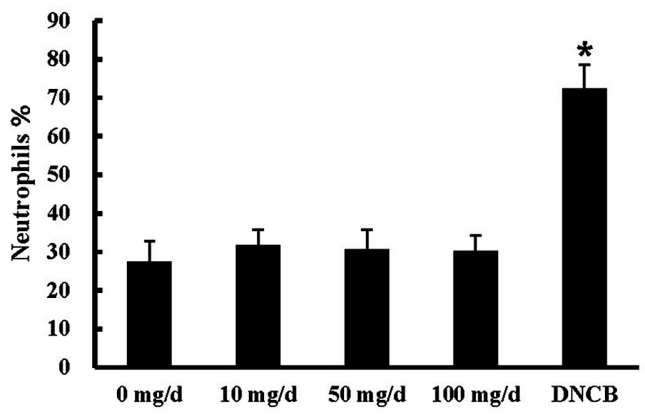

D

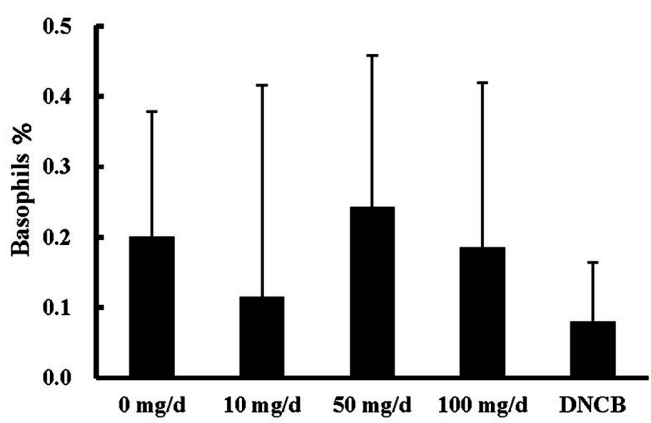

$\mathbf{E}$

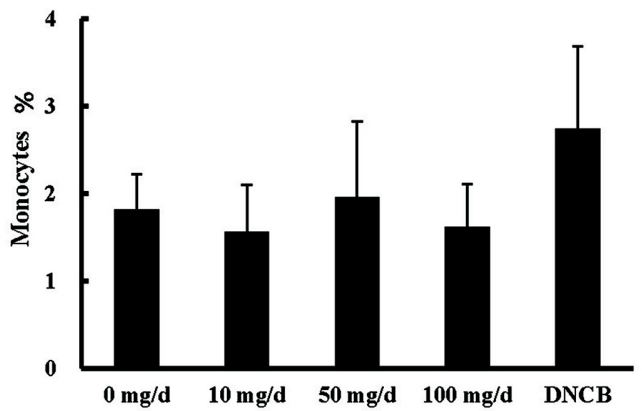

Fig. 1. Populations of lymphocytes, granulocytes, and monocytes. (A) Lymphocytes, (B) neutrophils, (C) eosinophils, (D) basophils, and (E) monocytes are presented as the percentages of blood cells. Statistical analysis was conducted between $0 \mathrm{mg} / \mathrm{d}$ (control) and each EW treatment in the same wk $\left({ }^{*} p<0.05, \mathrm{n}=10\right)$. EW: egg white; DNCB: 1-chloro-2,4-dinitrobenzene.

was significantly higher than that in the control group (Fig. 2). Recently, a study showed that chicken embryo extract enhances spleen lymphocyte proliferation and interleukin-2 secretion, while increasing peritoneal macrophage phagocytosis and nitric oxide production activity (Li et al., 2012). In addition, WSEYE significantly increases monocyte and B lymphocyte activity (Lee et al., 2013). Taken together, our data showed that EW consumption regulates $\mathrm{B}$ and $\mathrm{T}$ lymphocyte activation, suggesting that EW may be an immune activator.

\section{Effect of EW on immunoglobulin levels}

To investigate the ability of EW to modulate blood immunoglobulin levels in mice, serum IgG and IgE concen- trations in the blood were analyzed at 4 wk of EW treatment. Serum IgG levels in $100 \mathrm{mg} / \mathrm{d}$ EW- and DNCBtreated groups were significantly increased compared with that in the control (Fig. 3). The serum IgE concentration was not significantly altered among EW treatment groups (Fig. 3). However, the serum IgE level in the DNCBtreated group was significantly increased compared with that in the control group (Fig. 3).

Egg allergy is the most common food allergy in children with atopic dermatitis (Sampson, 2004). Food allergy is frequently the result of an IgE-mediated hypersensitive reaction, and the serum IgE level has a strong association with allergies (Burrows et al., 1989). In this study, serum IgE levels were unchanged in EW-treated groups com- 
A

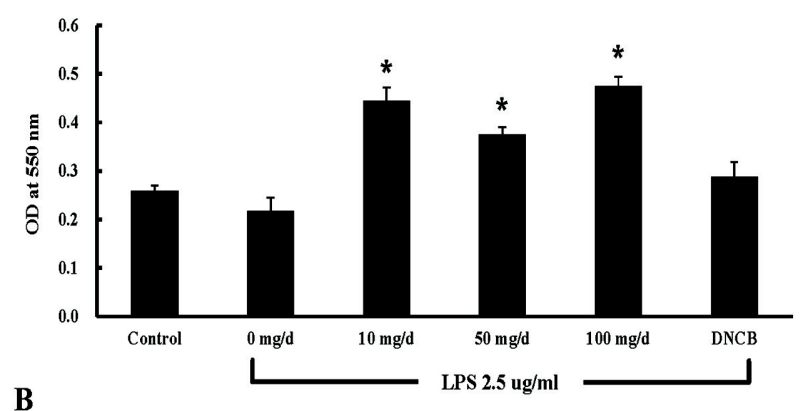

B

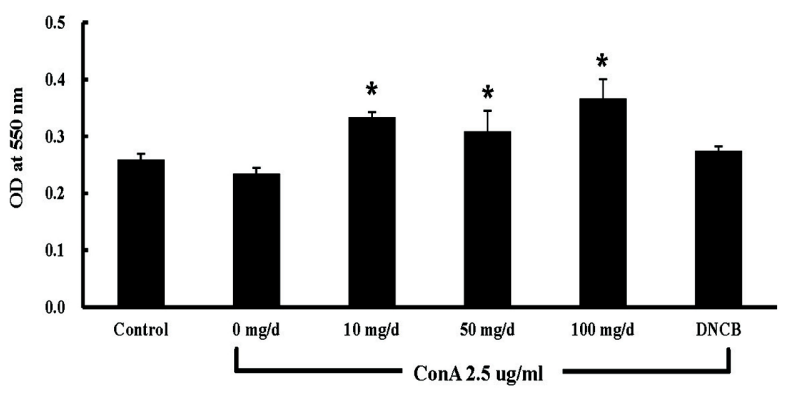

Fig. 2. B and T lymphocyte activation by egg white. Lymphocytes were isolated from $\mathrm{EW}(0,10,50$, and $100 \mathrm{mg} / \mathrm{d})$ treated mice at 4 wk. Isolated lymphocytes $\left(1 \times 10^{5}\right.$ cells $)$ were treated with (A) $2.5 \mu \mathrm{g} / \mathrm{mL}$ lipopolysaccharides (LPS) for B lymphocyte activation or (B) $2.5 \mu \mathrm{g} / \mathrm{mL}$ concanavalin A (ConA) for T lymphocyte activation. $p$-values were calculated between $0 \mathrm{mg} / \mathrm{d}$ (control) and each EW treatment at $4 \mathrm{wk}\left({ }^{*} p<0.05, \mathrm{n}=10\right)$. EW: egg white; OD: optical density; DNCB: 1-chloro-2,4-dinitrobenzene.

pared with those in the control group (Fig. 3). Although allergic reactions are most often IgE-mediated reactions, non-IgE mediated reactions have also been described (Uguz et al., 2005). The serum ovalbumin specific IgG concentration is reflected by egg consumption, indicating that dietary allergens affect the developing immune system (Vance et al., 2004). The oral administration of EW improves the non-specific phagocytic activity of neutrophils in weaning piglets and calves (Araki et al., 1993; Nakagawa et al., 1993). It should therefore enhance the host defense mechanism against infectious diseases. In this study, serum IgG levels in the $100 \mathrm{mg} / \mathrm{d}$ EW group were significantly increased compared with those in the control (Fig. 3). This result indicates that high consumption of EW promotes immune reactions.

Allergy studies using animal models have been limited because allergic diseases occur via various routes. Generally, allergic model animals are generated by genetic mutation or treatment with chemical allergens. DNCB induces an increase in the serum IgE level in a concentration-dependent manner (Potter and Wederbrand, 1995).
A

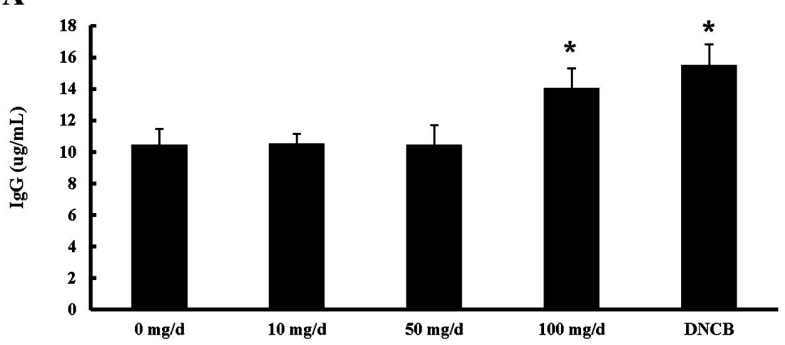

B

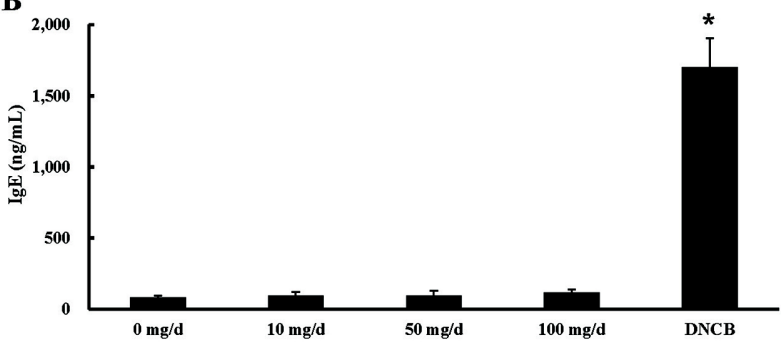

Fig. 3. Effect of egg white treatment on mouse immunoglobulin production. Blood samples were collected from $\mathrm{EW}$ $(0,10,50$, and $100 \mathrm{mg} / \mathrm{d})$-treated mice at $4 \mathrm{wk}$. The samples were incubated with anti-mouse $\operatorname{IgG}(\mathrm{A})$ and $\operatorname{IgE}$ (B) antibodies. A horseradish peroxidase-conjugated secondary antibody was used to detect the absorbance of each Ig. $p$-values were calculated between $0 \mathrm{mg} / \mathrm{d}$ (control) and each EW treatment at $5 \mathrm{wk}\left({ }^{*} p<0.05, \mathrm{n}=10\right)$. EW: egg white; DNCB: 1-chloro-2,4-dinitrobenzene.

Specifically, the increase in serum IgE levels were 2.5-, 3.5-, and 4-fold in 1-3\% DNCB-treated mice, suggesting that DNCB may be an optimal sensitizer to increase serum IgE concentrations. Allergic reactions vary among individuals. Some individuals do not have allergies to specific allergens that can induce an allergic reaction in sensitive individuals. In this study, treatment of mice with EW at various concentrations did not prompt allergic reactions in mice at 5-9 wk of age. At $5 \mathrm{wk}$ of age, male mice are similar to the post-pubertal stage of a male human, suggesting that consumption of EW does not induce an allergic reaction in post-pubertal humans.

\section{Effect of EW on serum lipid profiles}

Serum lipid levels were analyzed following ingestion of various concentrations of EW (Fig. 4). TC, HDL-C, LDL$\mathrm{C}$, and TG levels were not significantly changed among EW treatment groups over the experimental period (Fig. 4), but the level of serum HDL-C was significantly decreased in the DNCB-treated group (Fig. 4). In addition, LDL-C was significantly increased in the DNCB-treated group (Fig. 4).

A previous report showed that egg consumption must be limited to 3 eggs/wk to prevent coronary heart disease 
A

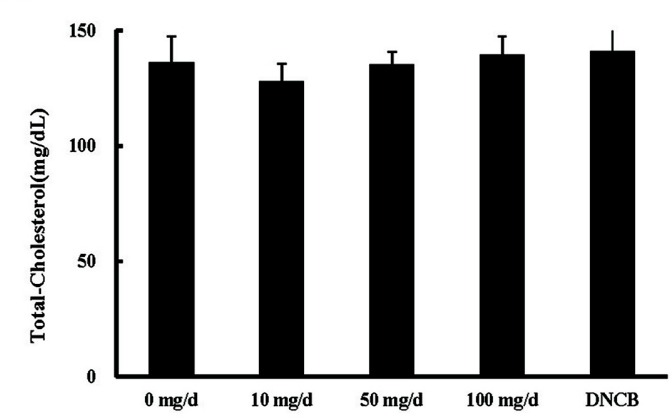

$\mathrm{C}$

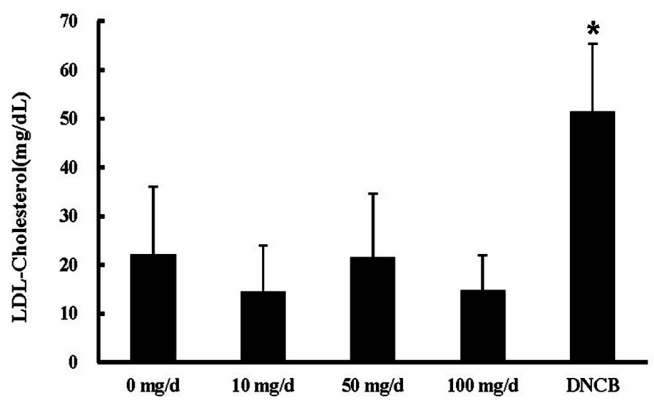

B

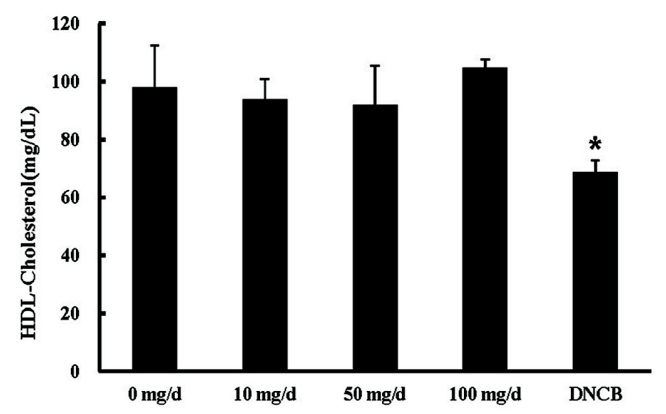

D

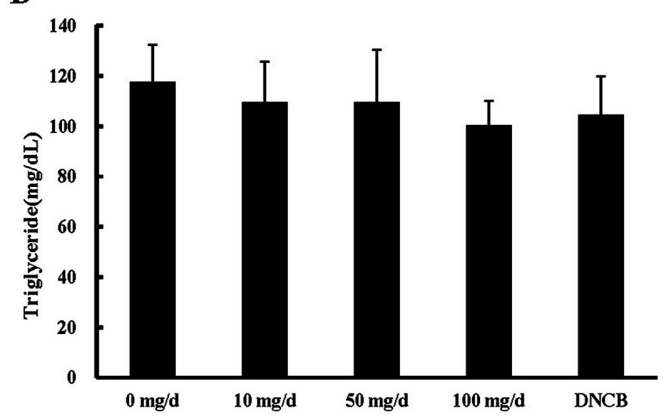

Fig. 4. Changes in serum lipid profiles by egg white treatment. $p$-values for (A) total cholesterol (TC) and (B) triglycerides were calculated between $0 \mathrm{mg} / \mathrm{d}$ (control) and each EW treatment in the same week $\left({ }^{*} p<0.05, \mathrm{n}=10\right)$. $p$-values for (C) low density lipoprotein cholesterol (LDL-C) and (D) high density lipoprotein cholesterol (HDL-C) were calculated between $0 \mathrm{mg} / \mathrm{d}$ (control) and each EW treatment at $4 \mathrm{wk}\left({ }^{*} p<0.05, \mathrm{n}=10\right)$. EW: egg white; DNCB: 1-chloro-2,4-dinitrobenzene.

(AHA, 1973). However, many researchers have refuted that dietary egg cholesterol consumption increases blood cholesterol levels. Some studies have suggested that dietary egg cholesterol consumption is not related to coronary heart disease (Howell et al., 1997; Krumholz et al., 1994; Lee et al., 2013) because the coronary heart disease risk is more related to LDL-C/HDL-C levels and not to the total cholesterol levels (Fernandez and Webb, 2008). In the present study, the serum HDL-C level was significantly reduced in the DNCB-treated group (Fig. 4), and its relation to NLR was higher in the DNCB-treated group than in the control group. Our data showed that EW consumption did not relate to serum cholesterol and lipid levels, suggesting that EW may be a safe food for patients with cardiovascular disease.

\section{Effect of EW on hepatic disease}

GOT and GPT are enzymes produced in hepatic cells. The levels of serum GOT and GPT are an estimated index of hepatic injury, because damaged hepatic cells secrete GOT and GPT into blood serum. The serum GOT and GPT concentrations were not significantly changed in EW treatment groups, but they were significantly increased in the DNCB-treated group (Fig 5). These data are also similar
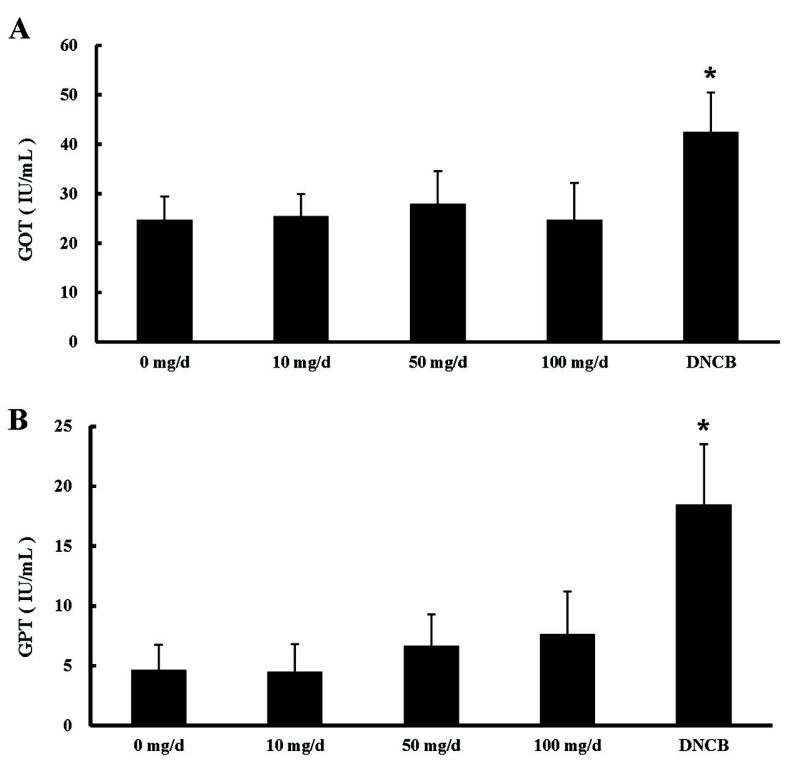

Fig. 5. Hepatic function test values of mice treated with egg white. $p$-values for (A) glutamic oxaloacetic transaminase (GOT) and (B) glutamic pyruvic transaminase (GPT) concentrations were calculated between $0 \mathrm{mg} / \mathrm{d}$ (control) and each EW treatment in 4 wk $\left({ }^{*} p<0.05, \mathrm{n}=10\right) \mathrm{EW}$ : egg white; DNCB: 1-chloro-2,4-dinitrobenzene.

to the results of a previous report indicating that egg intake 
does not affect GOT and GPT levels in serum (Lee et al., 2007). Taken together, these results suggest that EW intake does not show a relation to hepatic injury.

\section{Acknowledgements}

This work was carried out with the support of the Cooperative Research Program for Agriculture Science \& Technology Development (Project No. PJ008460), Rural Development Administration, Republic of Korea.

\section{References}

1. American Heart Association (AHA) (1973) Diet and Coronary Heart Disease. Dallas: American Heart Association.

2. Anet, J., Back, J. F., Baker, R. S., Barnett, D., Burley, R. W., and Howden, M. E. (1985) Allergens in the white and yolk of hen's egg. A study of IgE binding by egg proteins. Int. Arch. Allergy. Appl. Immunol. 77, 364-371.

3. Araki, S., Kimura, M., Suzuki, M., and Fujimoto, M. (1993) Effect of active egg white product on neutrophil function in weanling piglets. J. Vet. Med. Sci. 55, 899-900.

4. Bernhisel-Broadbent, J., Dintzis, H. M., Dintzis, R. Z., and Sampson, H. A. (1994) Allergenicity and antigenicity of chicken egg mucoid (Gal d III) compared with ovalbumin (Gal $\mathrm{d}$ I) in children with egg allergy and in mice. J. Allergy Clin. Immunol. 93, 1047-1059.

5. Burks, A. W., Jones, S. M., Wood, R. A., Fleischer, D. M., Sicherer, S. H., Lindblad, R. W., Stablein, D., Henning, A. K., Vickery, B. P., Liu, A. H., Scurlock, A. M., Shreffler, W. G., Plaut, M., and Sampson, H. A. (2012) Oral immunotherapy for treatment of egg allergy in children. N. Engl. J. Med. 367, 233-243.

6. Burrows, B., Martinez, F. D., Halonen, M., Barbee, R. A., and Cline, M. G. (1989) Association of asthma with serum IgE levels and skin-test reactivity to allergens. N. Engl. J. Med. 320, 271-277.

7. Fernandez, M. L. and Webb, D. (2008) The LDL to HDL cholesterol ratio as a valuable tool to evaluate coronary heart disease risk. J. Am. Coll. Nutr. 27, 1-5.

8. Friedewald, W. T., Levy, R. I., and Fredrickson, D. S. (1972) Estimation of the concentration of low-density lipoprotein cholesterol in plasma, without use of the preparative ultracentrifuge. Clin. Chem. 18, 499-502.

9. Heine, R. G., Laske, N., and Hill, D. J. (2006) The diagnosis and management of egg allergy. Curr. Allergy. Asthma. Rep. 6, $145-152$

10. Howell, W. H., McNamara, D. J., Tosca, M. A., Smith, B. T., and Gaines, J. A. (1997) Plasma lipid and lipoprotein responses to dietary fat and cholesterol: a meta-analysis. Am. J. Clin. Nutr. 65, 1747-1764.

11. Hu, F. B., Stampfer, M. J., Rimm, E. B., Manson, J. E., Ascherio, A., Colditz, G. A., Rosner, B. A., Spiegelman, D., Speizer, F. E., Sacks, F. M., Hennekens, C. H., and Willett W. C.
(1999) A prospective study of egg consumption and risk of cardiovascular disease in men and women. JAMA 281, 13871394.

12. Kritchevsky, S. B. (2004) A review of scientific research and recommendation regarding eggs. J. Am. Coll. Nutr. 23, 596600 .

13. Kritchevsky, S. B. and Kritchevsky, D. (2000) Egg consumption and coronary heart disease: An epidemiologic overview. J. Am. Coll. Nutr. 19, 549-555.

14. Krumholz, H. M., Seeman, T. E., Merrill, S. S., Mendes de Leon, C. F., Vaccarino, V., Silverman, D. I., Tsukahara, R., Ostfeld, A. M., and Berkman, L. F. (1994) Lack of association between cholesterol and coronary heart disease mortality and morbidity and all-cause mortality in persons older than 70 years. JAMA 272, 1335-1340.

15. Lee, C. U., On, J. H., and Koh, J. B. (2007) Effect of feeding eggs on levels of serum lipid, protein, and enzyme activities in rats. J. Life Sci. 17, 529-534.

16. Lee, W. Y., Lee, R., Kim, H. C., Lee, K. H., Noh, K. S., Kim, H. W., Kim, J. H., Ahn, D. U., Jang, I. S., Jang, A., Lee, H. T., and Song, H. (2013) Consumption of water-soluble egg yolk extract on growth rate, changes in blood cholesterol levels, and immune modulation in BALB/c mice. Korean J. Food. Sci. An. 33, 587-594.

17. Li, X., Su, Y., Sun, J., and Yang, Y. (2012) Chicken embryo extracts enhance spleen lymphocyte and peritoneal macrophages function. J. Ethnophamacology 144, 255-260.

18. Nakagawa, J., Osame, S., Ichijo, S., Araki, S., and Kimura, M. (1993) Effects of active egg white product on neutrophil function in calves. J. Vet. Med. Sci. 55, 259-263.

19. Ochiai, Mand Matsuo, T. (2014) Effect of egg white and its hydrolysate on stearoyl-CoA desaturase index and fat accumulation in rat tissues. Int. J. Food Sci. Nutr. 21,1-5.

20. Potter, D. W. and Wederbrand, K. S. (1995) Total IgE antibody production in BALB/c mice after dermal exposure to chemicals. Fundam. Appl. Toxicol. 26, 127-135.

21. Reitman, S. and Frankel, S. (1957) A colorimetric method for the determination of serum glutamic oxalacetic and glutamic pyruvic transaminases. Am. J. Clin. Pathol. 28, 56-63.

22. Rona, R. J., Keil, T., Summers, C., Gislason, D., Zuidmeer, L., Sodergren, E., Sigurdardottir, S. T., Lindner, T., Goldhahn, K., Dahlstrom, J., McBride, D., and Madsen, C. (2007) The prevalence of food allergy: a meta-analysis. J. Allergy Clin. Immunol.120, 638-646.

23. Safak, S., Savas, S., Lutfi, A., Fatih, A., and Kayihan, K. (2013) Evaluation of Neutrophil to Lymphocyte ratio as an Indicator of Presence of Coronary Artery Disease in Diabetic Patients. Natl. J. Med. Res. 3, 300-303

24. Sampson, H. A. (2004) Update on food allergy. J. Allergy Clin. Immunol. 113, 805-819.

25. Song, W. O. and Kerver, J. M. (2000) Nutritional contribution of eggs to American diets. J. Am. Coll. Nutr. 19, 556562.

26. Szepfalusi, Z., Ebner, C., Pandjaitan, R., Orlicek, F., Scheiner, O., Boltz-Nitulescu, G., Kraft, D., and Ebner, H. (1994) Egg yolk alpha-livetin (chicken serum albumin) is a cross- 
reactive allergen in the bird-egg syndrome. J. Allergy. Clin. Immunol. 93, 932-942.

27. Uguz, A., Lack, G., Pumphrey, R., Ewan, P., Warner, J., Dick, J., Briggs, D., Clarke, S., Reading, D., and Hourihane, J. (2005) Allergic reactions in the community: a questionnaire survey of members of the anaphylaxis campaign. Clin. Exp. Allergy 35, 746-750.

28. Vance, G. H., Grimshaw, K. E., Briggs, R., Lewis, S. A., Mullee, M. A., Thornton, C. A., and Warner, J. O. (2004) Serum ovalbumin-specific immunoglobulin $\mathrm{G}$ responses during pregnancy reflect maternal intake of dietary egg and relate to the development of allergy in early infancy. Clin. Exp. Allergy 34, 1855-1861.

29. Weggemans, R. M., Zock, P. L., and Katan, M. B. (2001) Dietary cholesterol from eggs increases the ratio of total cholesterol to high-density lipoprotein cholesterol in human: a meta-analysis. Am. J. Clin. Nutr. 73, 885-891.

30. Zahorec, R. (2001) Ratio of neutrophil to lymphocyte countsrapid and simple parameter of systemic inflammation and stress in critically ill. Bratisl. Lek. Listy. 102, 5-14.

(Received 2014.6.25/Revised 2014.8.22/Accepted 2014.8.25) 